\section{Entrepreneur recognised}

Dentist Neil Sikka, owner of Barbican Dental Care, was named Entrepreneur of the Year 2005 this year's Asian Business Awards. The ceremony acknowledges the contributions and achievements of British Asian business people who have built multi-million pound businesses. Dr Sikka's firm treats over 30,000 clients per year in four dental practices across London and also acts as a company dentist for large corporate firms.



\title{
Dental award winners 2005
}

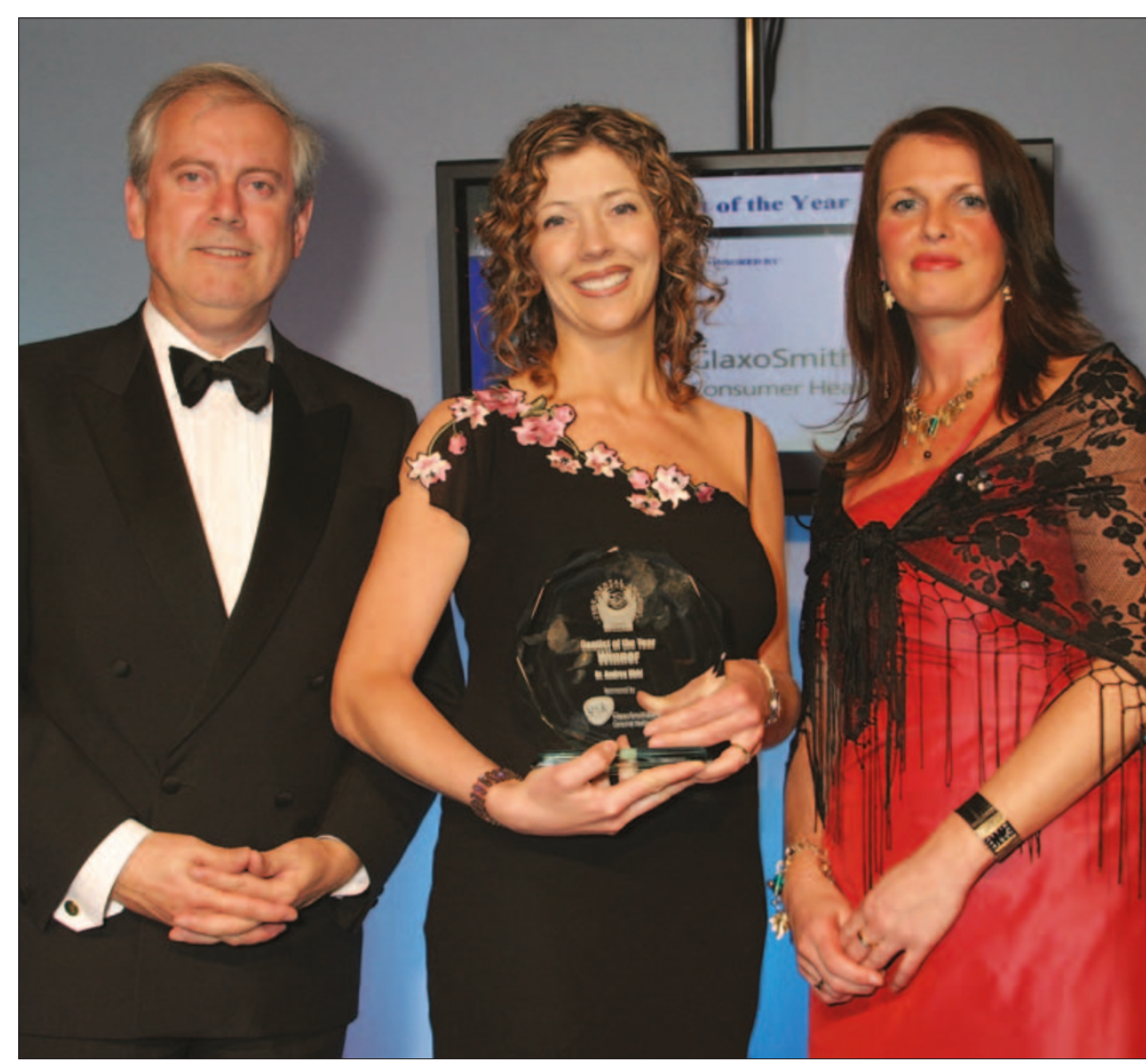

Yorkshire dentist Dr Andrea Ubhi picked up the Dentist of the Year award at the Dental Awards 2005, which took place last month in London. Dr Ubhi runs a private cosmetic dentistry practice in York, and developed her passion for cosmetic dentistry after visiting the USA where she learnt techniques in porcelain laminate veneers and tooth whitening. The Outstanding Achievement award was presented to John Renshaw, Chair of the BDA's Executive Board. He is a general dental practitioner in Scarborough, North Yorkshire, has served on two health authorities and was a member of the NHS Plan Access Task Force. Other winners included the Bristol Endodontic Clinic, Bristol, for best practice environment, dental practice Thompson \& Thomas, Sheffield, for the People's Award for Patient Care and The Crescent Specialist Dental Centre, Devon for Best Dental Team Support Programme. The event was organised by The Probe and the British Dental Health Foundation. Pictured left to right, compere for the evening, Gyles Brandreth, Dr Andrea Ubhi and Vicky Hampson, Healthcare Professional Relations Director at GlaxoSmithKline.

\section{Change of name}

The Faculty of General Dental Practitioners (UK) has changed its name to the Faculty of General Dental Practice (UK). It says the move was prompted by its introduction of a membership category for professionals complementary to dentistry. The change of emphasis in the new name is designed to encompass all members of the dental team.

The organisation's aim is to improve the standard of care delivered to patients through standard setting, postgraduate training and assessment, education and research. 


\section{Fluoride}

\section{information}

\section{centre}

\section{launched}

England's first independent fluoride information centre based at the University of Manchester has been launched to meet an anticipated public demand for information following changes to the Water Bill.

The National Fluoride Information Centre (NFIC) has been established by scientific experts and will offer advice on fluorides and fluoridation following a recent government move which could see water fluoridation schemes implemented across the country.

NFIC Director, Professor Anthony Blinkhorn said, "We are the only information centre in England providing objective information on fluorides. As the national focal point for disseminating

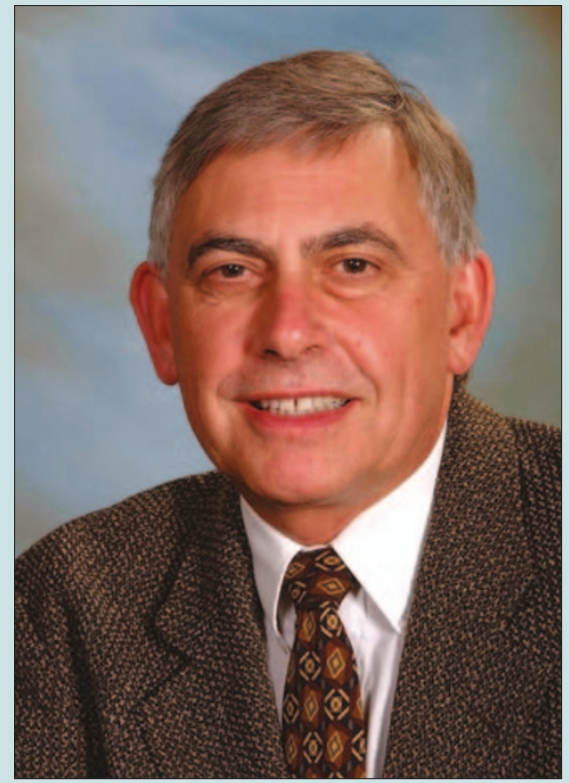

scientifically accurate information on fluorides, we offer unbiased information based on scientific literature".

The centre will have an online information resource at www.fluordeinformation.com for people wanting to find out more about fluorides and fluoridation will also operate a telephone helpline.

\section{Boost for Welsh NHS dentistry}

An extra £5 million aimed at keeping dentists in the Welsh NHS has been announced by the Welsh Assembly Government. The money will pay for a series of Personal Dentist Service (PDS) pilots which would allow dentists and local health boards to introduce local contract arrangements.

Health Minister Dr Brian Gibbons said the money would be used to develop access to dental services and to compensate dentists who introduce the scheme as they would then receive less payment than they would if they had continued on the 'fee per item' system.

Half the population of Wales is not registered for NHS dental care which has meant long queues at dental surgeries. In 2003, around 600 people waited outside a Carmarthen dental practice to register for NHS treatment.

\section{Mother and child health}

The importance of good oral health was a key topic on World Health Day 2005, organised by the World Health Organisation. The event, which took place in April, focused on the health of mothers and children with the theme 'Make Every Mother and Child Count'.

In response to the event, the FDI World Dental Federation claims that mothers (as all other women) and children are amongst the most vulnerable of all populations around the world and often experience higher levels of ill health and limited access to care. The Federation asserts that greater prominence needs to be given to equal provision of basic human rights, which include the right to good general and oral health.

"Good oral health is a basic human right and inseparable from general health and wellbeing. Only by taking a holistic approach to health promotion, by addressing risk factors that are shared by systemic and oral diseases, can we succeed in achieving improved levels of oral health for mothers and children" said Dr JT Barnard, FDI Executive Director.

The Federation supports action to



improve the health of mothers through asserting their basic human rights, including access to health care, education, employment opportunities and safe and healthy environments.

It adds that all health professionals, such as physicians, dentists, nurses or midwives, need to be aware of the seri- ous impact of oral diseases on health, nutrition and wellbeing of mothers and children and believes that the promotion of oral health should to be part of all health education programmes and appropriate oral health care services for children and their mothers should be available. 


\section{New report on fluoridation}

The British Fluoridation Society, UK Public Health Association, British Dental Association, and Faculty of Public Health have published a new report about water fluoridation.

One in a Million is endorsed by the Chief Dental Officer (England) Professor Raman Bedi, and the British Medical Association, and objectively reviews the scientific facts about fluoridation, to help local NHS decision makers to consider whether to implement new schemes in their areas.

Subsequent to the Water Act 2003, in March 2005 Parliament approved Regulations on how Strategic Health Authorities should consult local people on the decision to fluoridate water supplies and the Regulations came into effect on 1 April 2005.

Ten thousand copies of One in a Million are being distributed through Strategic Health Authorities in England, and through single contacts in Wales, Scotland and Northern Ireland.

According to Dr Peter Tiplady, Chair of the BMA's Committee for Public Health Medicine and Community Heath, the report will be an invaluable source of information for Strategic Health Authorities and Primary Care Trusts, when they consult their local communities about water fluoridation.

\section{Electric toothbrushes not always better}

Manual toothbrushes are as good as electric toothbrushes, according to a study published by the Cochrane Library.

The review of 42 trials showed that in most cases manual toothbrushes removed as much plaque as their more expensive electronic counterparts, and protected just as well against inflamed gums. The study, led by Professor Peter Robinson of the University of Sheffield, claimed that the only type of electric toothbrush more effective than a manual brush was one with a rotating-oscillating head.

It also found that only brushes with circular heads that move a quarter turn in one direction and then back a quarter turn, clean better than a traditional toothbrush. Professor Robinson explained, "People with electric toothbrushes that don't have rotatingoscillating heads shouldn't worry, as it won't be doing them any harm. However, if they bought an electric toothbrush to get their teeth as clean as possible then it is worth investing in a brush

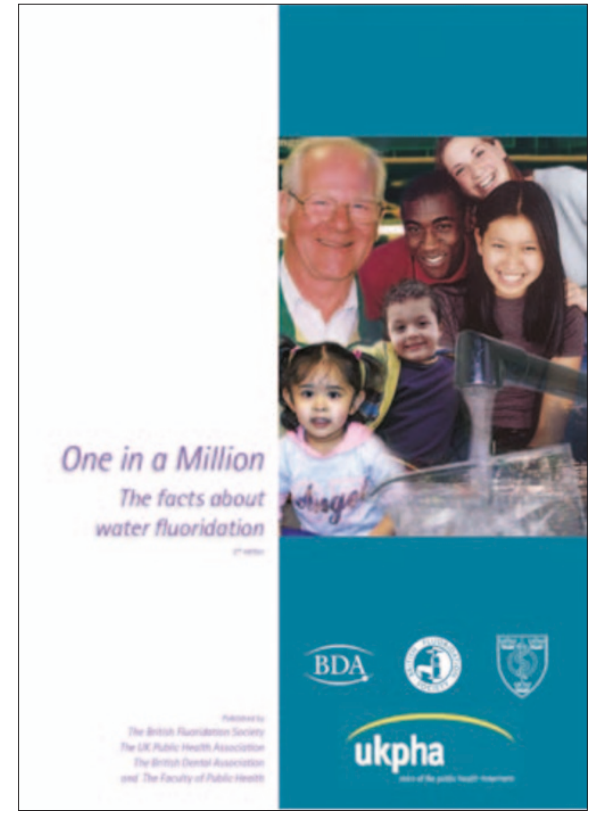

He commented, "Children in non-fluoridated parts of the North of England have, on average, twice as much tooth decay as those in similar areas where the water supply is fluoridated. Clearly targeted water fluoridation can help to close that gap."

The report is available electronically on the British Fluoridation Society website www.bfsweb.org.

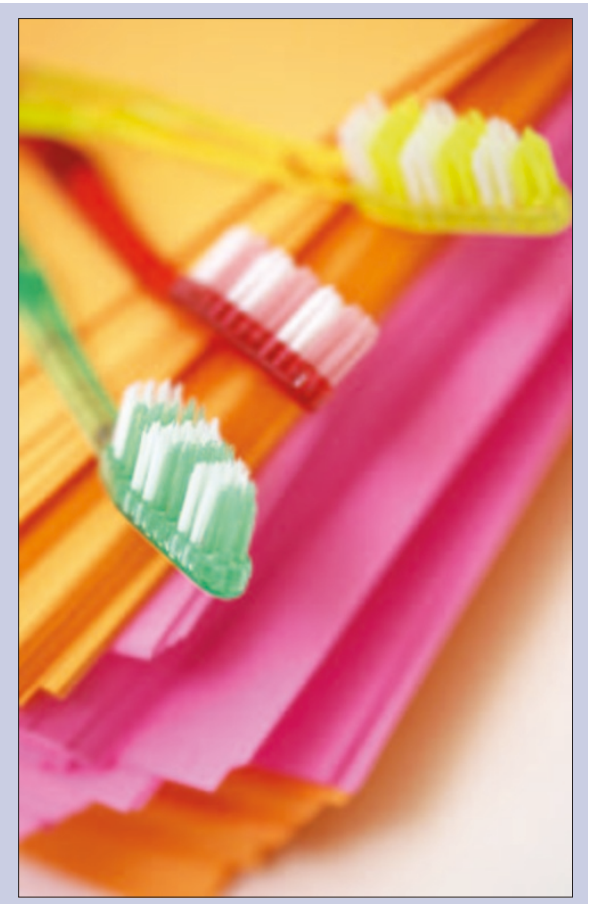

with a rotating-oscillating head."

The authors of the report asserted that people may be wasting money on toothbrushes they believe will clean their teeth better, when a much cheaper traditional brush would do the job just as well. 